$10-1-2020$

\title{
Changes in Health Care Following COVID-19.
}

David B. Nash

Thomas Jefferson University

Thomas H Lee

Press Ganey, LLC, Harvard Medical School

Leana Wen

The George Washington University

Bruce A Meyer

Thomas Jefferson Universit

Judd E Hollander

Thomas Jefferson University

Follow this and additional works at: https://jdc.jefferson.edu/healthpolicyfaculty

See next page for additional authors

Part of the Public Health Commons

Let us know how access to this document benefits you

\section{Recommended Citation}

Nash, David B.; Lee, Thomas H; Wen, Leana; Meyer, Bruce A; Hollander, Judd E; and Skochelak, Susan, "Changes in Health Care Following COVID-19." (2020). College of Population Health Faculty Papers. Paper 103.

https://jdc.jefferson.edu/healthpolicyfaculty/103

This Article is brought to you for free and open access by the Jefferson Digital Commons. The Jefferson Digital Commons is a service of Thomas Jefferson University's Center for Teaching and Learning (CTL). The Commons is a showcase for Jefferson books and journals, peer-reviewed scholarly publications, unique historical collections from the University archives, and teaching tools. The Jefferson Digital Commons allows researchers and interested readers anywhere in the world to learn about and keep up to date with Jefferson scholarship. This article has been accepted for inclusion in College of Population Health Faculty Papers by an authorized administrator of the Jefferson Digital Commons. For more information, please contact: JeffersonDigitalCommons@jefferson.edu. 


\section{Authors}

David B. Nash, Thomas H Lee, Leana Wen, Bruce A Meyer, Judd E Hollander, and Susan Skochelak 


\section{Changes in Health Care Following COVID-19}

Moderator: David B. Nash, MD, MBA ${ }^{1}$

Participants: Thomas H. Lee, MD, MSc, ${ }^{2,3}$ Leana Wen, MD, MSc, ${ }^{4}$ Bruce A. Meyer, MD, MBA, ${ }^{5-7}$ Judd E. Hollander, MD, ${ }^{8,9}$ and Susan Skochelak, MD, MPH ${ }^{10}$

${ }^{1}$ College of Population Health, Thomas Jefferson University, Philadelphia, Pennsylvania, USA.

${ }^{2}$ Press Ganey.

${ }^{3}$ Harvard Medical School, Boston, Massachusetts, USA.

${ }^{4}$ The George Washington University, Washington, District of Columbia, USA.

${ }^{5}$ Jefferson Health.

${ }^{6}$ Thomas Jefferson University (TJU).

${ }^{7}$ Sidney Kimmel Medical College at TJU, Philadelphia, Pennsylvania, USA.

${ }^{8}$ Healthcare Delivery Innovation.

${ }^{9}$ Strategic Health Initiatives, Thomas Jefferson University, Jefferson Health, Philadelphia, Pennsylvania, USA.

${ }^{10}$ American Medical Association, Chicago, Illinois, USA.

Important notice: This conversation was held on June 17, 2020, and the resulting transcript reflects the events that were current as of the time of the original discussion. Changes to policies, events, and data may have changed between the time of the discussion and its publication.

DR. DAVID B. NASH: Thank you, colleagues, for joining us for this second roundtable for Population Health Management's dedicated special issue on COVID-19. I want to thank you all for carving time out of your super-busy schedules and really, personally, it is just a treat for us to be together. Dr. Lee, you have been so deeply thoughtful about the word "trust." When I think about the last 90 days at the local, regional, and national levels, what can you say about this trust factor that people have in us and our system in delivering care? I would like to start off getting your sense of where our level of trust is today in the health care system. 
DR. THOMAS H. LEE: I am glad you started with that question, because it is something really fundamental. I would say that at the beginning of 2020, all of us took trust for granted. We did not really talk about trust very much. But now "trust" is the word on the tip of everyone's tongue, even though the concept of fuzzy to many. The definition I like for "trust" is confidence you are going to be treated fairly in situations you have not even thought of yet.

Times of transition are when trust really gets tested. These are the times when we can determine who has earned trust and who has not. For organizations, it is a competitive differentiator to have trust--trust by patients, but also trust by the workforce, by your doctors, your nurses and your other personnel. These are issues that organizations are really grappling with as they navigate the redesign of care in a time of incredible change. I would say that we are doing pretty well, but we have plenty of work to do. It is an important and timely issue as never before in my career.

DR. NASH: I love the notion, Dr. Lee, of a competitive differentiator. I have to ask Dr. Meyer, Jefferson Health's most senior physician leader, who is on television almost every day now in - in Philadelphia talking specifically about how viewers can trust Jefferson's delivery system because we focused on making our providers safe, which enabled us to keep our patients safe. So, Dr. Meyer, I think that is a perfect segue for you to connect the dots to what Dr. Lee just discussed to talk about Jefferson's ability to deliver on the trust.

DR. BRUCE A. MEYER: I think Dr. Lee makes an incredibly important point, which is that if our staff cannot trust us, then our patients cannot trust us, so we really work very hard to figure out how we can keep staff safe during the COVID-19 pandemic and how to minimize their risk. We cannot eliminate it, but how do we reduce their risk to the absolute minimum? And how do we communicate effectively with our staff about what we are doing to minimize their risk?

We have a lot of data and we have now pivoted to be able to talk to the community about how we have kept our staff safe as well as how we have kept the nonCOVID patients separated and safe from the COVID patients so that we did not in fact increase the pandemic by cross-exposure. 
DR. NASH: Dr. Meyer, can you give some numbers to what you were talking about most recently on television, as well? I think that would be impressive.

DR. MEYER: Sure. Only about 1\% of our staff have become infected with COVID-19 during the pandemic, and we can trace at least half of those cases to communityacquired situations. We have only had to hospitalize 32 of our 35,000 staff members throughout the pandemic, which is a very small ratio. And although we have lost two of our staff members to the disease, the numbers across the board for us are relatively small compared to what we see, especially coming out of Europe and with the institutions of other colleagues around the country.

Jefferson has really paid heavy and careful attention to trying to ensure that we have proper PPE. We went to an all-mask environment very early, in the third week of March of 2020. Anybody entering our hospitals or ambulatory facilities must wear masks throughout the entire time that they are in the building, for any reason.

DR. NASH: Dr. Wen, mayors, commissioners of health, and regional leaders who quite frankly most people never pay too much attention to are currently finding themselves in the limelight. You were once in this limelight yourself in Baltimore. You know what it is like to handle murders and public health emergencies from this perspective. Coming from someone with your perspective and experience, what is your position on the importance of local public health leadership, and what do you think about what you have observed around the country, especially in the last 90 days?

DR. LEANA WEN: Thank you for convening this conversation. One of your other panelists, Dr. Karen DeSalvo, said -- and I remember this so well -- that public health saved your life today. You just do not know it.

I think about that a lot because when I was the Health Commissioner I had to get people to pay attention to public health. No one runs a campaign for mayor to be a public health mayor. Maybe they might now, after COVID-19, but they certainly did not before. Because public health is successful when we, by definition, prevent something from happening, it makes it so that there is no face of public health. Our work is invisible. And when it is invisible, no one cares about it, and so it becomes the first thing on the chopping block. 
In fact, that is what we have seen. We have seen this disinvestment in public health that has been detrimental. We have lost around $20 \%$ of our local public health workforce in the last two decades. ${ }^{1}$ The money that the CDC and the federal government allocates to local public health has consistently declined despite the increasing needs.

We are seeing all this coming back to roost when we see that, in the face of this biggest public health crisis of our lifetimes, we do not have the infrastructure in place to handle COVID-19. Now we are seeing that health departments cannot handle their other duties because all the resources are diverted to COVID.

We are now trading off all the work on cardiovascular disease and on opioids and on maternal health to focus on COVID-19, which, of course, makes no sense.

I hope that after we have a chance to recover from COVID-19 and look at the lessons learned that one of the things that we will do is to really invest in public health, because now there is a face of public health, finally. But in the meantime, I really worry about how science and public health have been sidelined.

One would think that in the middle of a public health crisis that the people leading should be public health experts. One would think also that science and data should be driving decision-making, but unfortunately that is not what is happening. I am not trying to make a partisan statement at all, but rather, this is objectively what is happening, and unfortunately, the consequence is going to be more preventable infections and more preventable deaths.

DR. NASH: We are going to come back later to talk about the chasm between health care delivery and public health, a really important phenomenon, which goes back decades. We are going to come back to how to integrate public health education into medical education as well. I think the public is going to want to know how we are preparing doctors in a different way for the future. Before we get to those, Dr. Meyer has something to share. Dr. Meyer?

DR. MEYER: I would just like to amplify the point that Dr. Wen made, which is, we are deeply concerned in a greater way about a second wave of poor health care outcome as opposed to a second wave of COVID-19. We saw 40\% decreases in Emergency room visits and admissions for stroke and MI, while DOA calls to 911 more than doubled. People are clearly frightened to come to the ER for fear of COVID and it is 
having health consequences.

DR. NASH: Dr. Meyer, thank you. And Dr. Lee, it's great that we have some data, and Jefferson Health, with our 14 hospitals, has been looking at what others have called the untold burden, the institutions and leaders that did not show up, and what the downstream consequences are going to be. The October 2020 issue of Population Health Management has more on this, with some good details.

We heard Dr. Wen talk about the gap between public health and health in the sense that when public health is successful, nobody pays too much attention. I like to say the only time people care about public health is when there's widespread food poisoning centering around their favorite restaurant. Then they want action. Otherwise, we assume that the system is working well.

But the coronavirus pandemic has pointed out so many shortcomings, among them the lack of understanding even among providers about some of the basic tenets of epidemiology and behavior, for instance. So, Dr. Skochelak, you are in the catbird seat at the American Medical Association. Where do you see the impact on both undergraduate and graduate medical education as it relates to some of this content?

DR. SUSAN SKOCHELAK: Thank you. The COVID-19 pandemic has unearthed holes in the health care system, but similarly, it has unearthed holes in the medical education system. For the past five years, we have been working with a consortium of medical schools and now graduate medical education program to point out what is missing in teaching our future providers. This relates to the third pillar of medical education, which we have called health system science. Health system science includes key content that physicians need to optimize the health of our populations. It includes population medicine, social determinants of health, leadership and change, managing teams, value-based care, and other related topics. These subjects have historically been missing from medical education, as we've historically only taught the two pillars of basic and clinical sciences. But now the leading schools are adding these areas to their curriculum. As much as $30 \%$ of their full curricula are devoted to the content of health system science.

Dr. Nash, ironically, we wrote a chapter in the second edition of our textbook, "Health System Science," which included a future scenario in which a pandemic swept 
across the United States, and medical students joined in and helped out by doing contact tracing and community interventions. We really have a long way to go in medical education, but there are many schools and programs on the forefront that are working hard in this area now.

DR. NASH: Today is orientation for all new house officers at Jefferson Health. I cannot imagine what these newcomers must be experiencing. It is stressful enough to go through orientation, and everybody on this phone call remembers his or her first day of internship. I cannot imagine what they are going through.

So, from your national perch, how did we make this transition? How did we get students, especially in the third and fourth year, out of the hospital, and now we are putting these trainees right back in to start internship? Can you give us some insights at the national level? What went on behind the scenes as we were going through this incredible transformation?

DR. SKOCHELAK: I am going to hearken back to Dr. Lee's comments about trust. In May, in April, even back in March of 2020, we heard from our learners around the country that they felt trust was breached in many areas of education. They were pulled from their rotations. They were worried that they were not going to graduate or leave their residency training in time, they would not qualify for certain milestones that we have put in place, like national testing, US Medical Licensing Examination (USMLE), Medical College Admission Tests (MCATs), and other things. Really, they are concerned about the deep disruption in the system.

One of the ways in which the medical education community came together was to bring all of the organizations across the accrediting and regulatory spaces through a group called the Coalition for Physician Accountability. The Coalition developed a number of national guidelines to try to stabilize the disrupted educational processes.

For example, this year, students will not be doing in-person interviewing for residency. They will be interviewing via online video. They will not be doing away rotations. Because of the possibility of the geographic transfer back and forth of students to different health systems, they cannot do audition rotations.

This has really changed the way in which those students, particularly those who are entering their fourth year, will match for residency. We have had to come together as a national community to set forth guidelines around PPE, around travel, around 
interviewing, and around expectations of training so that these students and residents feel that they are in good hands, and they can trust their leaders and the health care systems they train in it. Our hearts go out to those students as they are right on the front lines of COVID-19.

\section{DR. NASH: We are going to have to watch this generation and do some surveys} and some qualitative research to really understand the short-term and long-term impacts on these young people. I had 40-plus seniors from Sidney Kimmel Medical College with me every day in April and May. I felt I was doing group therapy more than I was talking about the tenets of health policy, epidemiology, and quality. I found it just remarkable how resilient these young people really are, and I tried to put myself in their place. I could not do it. So it helps to be young, that is for sure, when you are facing these kinds of crises.

DR. SKOCHELAK: Dr. Nash, may I just make sure to say, students and residents have done remarkable things during this pandemic. I want to credit them with all the work that they have done locally and regionally. So even though I am bringing a message of concerns and issues of trust, they are admirable in the way they have risen to the challenge.

DR. MEYER: I would like to add that I am the father of a son-in-law who started his internship during the era of COVID-19, and a daughter who is in her fellowship. I would not underestimate the high level of anxiety of these learners. That is not to say they have not stepped up in a profound way and tried to really be helpful, but it is anxiety-provoking when you are beginning your training or you are in the midst of training, and a pandemic sweeps through, and you can see the learning going on among your mentors and your faculty members right as you are learning yourself.

What I wonder is, how does that translate into what Dr. Lee described earlier in terms of trust? Because one of the things that I think learners profoundly benefit from is the global idea that the medical and the health care professions are trustworthy overall. At this time, I wonder whether that trust gets shaken a bit, and what does that mean for us long term in terms of people's self-identity and how they interact with patients in a world where all of our visual and social cues that help us read each other's behavior is interfered with because we are all wearing masks, and we are all wearing gear that 
prevents us from reading physical cues and that kind of thing.

Trainees are coming into a very, very different learning environment, and so are our patients.

DR. NASH: Yes, those are two great points. Given the different environment, I want to go to Dr. Hollander. So, Dr. Hollander, since before COVID-19, you have been a national leader in bringing technology to bear specifically in telemedicine with the American Telemedicine Association, with the journal that you have brought academic rigor to this field before it was in the national limelight. I know people are anxious to hear from you about what was the transition was like from pre-surge to surge, and I'm also hoping you can speak to how you grew the telemedicine team at Jefferson.

DR. JUDD E. HOLLANDER: The one word that would encapsulate it is actually "stressful," if I am being honest. I have been fortunate that I have had great leadership, that I work under Dr. Meyer, who is on this panel, and Dr. Steve Klasko, whose vision about telemedicine gave me a four- to five-year head start to grow out a telemedicine program before we needed to scale up overnight in response to COVID-19.

Unlike a lot of other places, Jefferson went all in. We had virtually every provider, every specialty, everything you could imagine, doing some degree of telemedicine, so when we had to ramp up for COVID, we appeared visionary. We never anticipated a pandemic was coming, but we thought value-based care was coming. It turns out the telemedicine vision aligned nicely.

But let me tell you, there are early adopters and there are people who are slow to adopt. Our early adopters took the ball and ran with it right away. You can imagine the one-third of providers who did not want to do telemedicine now all wanted to be trained right away. There were some logistical hurdles to overcome, but let me share with you two sets of numbers. In one of our primary care groups in New Jersey, they historically performed about 125 visits per month, but that grew to be around 6,000 in March of 2020. And we switched gears in the middle of the month, so this is an unbelievable accomplishment.

Our internal medicine group in Center City, Philadelphia, would do about 1,000 visits a day. A small handful of them would be telemedicine. Within a given weekend, obviously, the in-person visits plummeted a bit, but we were able to maintain about 
two-thirds of our visits, and we went from a single-digit percentage of telemedicine to $90 \%$ telemedicine.

Within that, there were technical challenges, but there are also challenges in communicating via video. We had to teach people how to show empathy, how to be caring, how to do a physical exam, and how to make patients that had technical difficulties feel like they were not the problem, that it was not their fault. I could go on forever, but I will not. There were challenges, but we were fortunate that we had a good head start, and we rolled over fast from in-person to telemedicine, so we were able to care for, most importantly, all of our non-COVID patients and make them feel safe, as well as our COVID patients.

DR. NASH: Dr. Hollander, that is an important point that Dr. Meyer and others were talking about earlier, that one of the ways we stayed in touch with the nonCOVID patients who had a high level of fear and distrust was using the technology. That was very important. While you have the floor, one of the concerns that $I$ have about this gigantic ramp-up activity in telemedicine is that many organizations and systems will not be able to navigate this change as seamlessly. By this I mean that I am confident that, for example, a Jefferson practitioner is going to do a good job in his or her interaction. I don't know that I feel other organizations and systems and for-profit companies who might be in this field will be up to the same standard. So, my question is as follows. Where do you see quality measures and outcome measures as it relates to delivering digital health and telemedicine? Where is that going to go? What kinds of measures will we be able to be accountable for to the public to demonstrate that we are doing a good job?

DR. HOLLANDER: That is a great question, and that is critical. I was fortunate enough to be chairing a group from the National Quality Forum that developed a measure framework for telehealth a couple years ago. It was a group of people who were smarter than me and who had more experience than me informing the process. It basically comes down to four domains that people think are important. They are obvious: access, cost and financial analysis, experience, and effectiveness.

I like to say telemedicine is best encapsulated by one statement. It is just a care delivery model. There is not telemedicine care. You get cardiology care. The only 
difference: the cardiologist is delivering care to you while they are wearing contact lenses, or eyeglasses, or inserted a video screen between you and them. The quality measures need to align in part with the goals that can be achieved using the technology, and more importantly, whether you are delivering the appropriate content-specific care.

If you are dealing with someone with sinusitis, for instance, the quality measures for telemedicine are the same as the quality measures with an in-person visit. They can be assessed using the Choosing Wisely guidelines for patients with this condition. The difference is, we now need to both scaffold the education and training into the curriculum, as Dr. Skochelak spoke about, and then we need to scaffold the quality programs into each department or division with the content expertise to make sure that quality metrics are being met for that disease. So I, as a telemedicine expert, cannot do quality in urology because I know nothing about urology quality. I need the urologists to learn how to do telemedicine quality the same way they do other quality within their division or department for in-person visits.

\section{DR. NASH: That is really a thoughtful answer, Dr. Hollander. Do you think the National Quality Forum measures are going to go forward as it relates to telemedicine? Can you give us an update on their status?}

DR. HOLLANDER: The NQF report provides more of a measure framework. The simplest way to think about it is this: if you have a cardiovascular measure that indicates to give people a statin if their cholesterol or lipid profile is above a certain point, it might actually say they need to have a visit. All we need to do is say a telemedicine visit can count as that visit. I think we can take the thousands of measures that exist and indicate that achieving them by telemedicine is suitable without needing to appear to mandate an in-person visit. I think if we just get clarification over what a visit is, even if it is a text message visit, we can achieve the outcome. We should not limit the definition of the visit is to achieve the desired outcome.

It should not be that hard unless people can't overcome to obstacle of thinking of telemedicine as something different from seeing a patient in the office. But it is not. Again, it is just a care delivery mechanism.

DR. NASH: I really like your framework, and I think that is going to be helpful. 
DR. LEE: I think the work that Jefferson Health and Dr. Hollander have been doing in this area is fantastic, and it has helped accelerate the spread of telemedicine. Now that telemedicine is really big, one thing that is dawning on a lot of us is that safety has to be thought about in the same way that we think about safety in operating rooms.

At Press Ganey, we started a national patient safety organization (PSO) PSO a year ago, and we are going through our first 3,000 COVID-related safety events now. Tejal Gandhi is leading the analysis. Most of these safety events are actually workforce safety events, where it was the workforce that was either put at risk actually suffered harm. We are realizing that there is a new world of telemedicine safety improvement that we will all eventually end up with, although I would guess Jefferson is probably going to be there faster than other institutions.

DR. NASH: Connecting these dots is really important, and there has been some really interesting recent literature about reemphasizing safety. And as Dr. Meyer pointed out early, when Jefferson put the focus on staff safety, that had ripple effects. In fact, the incident command structure, the daily huddle, the publishing of daily guidelines, and other measures put into place by Jefferson sounds a lot to me like quality improvement and performance improvement. People are now embracing measures that many people on this session have spent decades trying to implement. There's nothing like a 90-day burning platform to make some progress in this arena.

When I look around the world at how other countries are doing testing, tracing, and quarantining, and I compare their performance to our country's performance, boy, do we fall short in our ability to do widespread testing and widespread contact tracing. Dr. Wen, I would really like to hear your perspective on these two critical areas that we are certainly not done with by any means.

DR. WEN: You know, you are right. Of course, when we look at other countries that have been more successful in containing COVID-19, there are several things that they have done that unfortunately our country has not.

Those things include having a national coordinated strategy, whereas in this country we have had this piecemeal approach. I still cannot believe this, but as all of you know, states are bidding against each other for PPE and ventilators. In my state, which is Maryland, our governor had to procure tests from South Korea. When does a 
state negotiate with a foreign country? After getting 500,000 tests from South Korea, these tests were held in an undisclosed location, protected by the National Guard, to prevent the federal government from confiscating these tests. I mean, that is how ludicrous it is for us to not have a national strategy.

And of course, the consequences of this fall on our frontline health care workers who did not have necessary equipment, and we still are not nearly prepared for if we have another surge in cases. We also, of course, have not had clear, direct communications. There has been muddled messaging and even contradictory messaging and messaging that goes directly against public health.

The other component that Dr. Nash mentioned is also really important to talk about, which is, how have other countries been able to rein in the infection? Well, we have been talking in this country a lot about social distancing and shutdowns and these overall lockdowns that have saved lives, but really are that blunt instrument. That is what we had to do when the precision instruments could not work anymore. And the precision instruments actually are testing, contact tracing, quarantining, and isolation.

That is ideally what we would have been able to do at the beginning of this outbreak. If we had sufficient testing at the beginning, one can make the argument that we could have reined in the infection at that point, as other countries like South Korea, Singapore, and Taiwan were able to do. There were many other examples of jurisdictions and countries that were able to rein in the infection by finding every positive case, identifying all the contacts that they were exposed to during their infectious period, and then isolating those, even building facilities for people who had no other way of isolating and quarantining all those contacts, as well. That is how, according to Tom Frieden, to box in the infection.

In America we had to, unfortunately, resort to the overall societal shutdowns, that blunt instrument, because we could not do the precision instrument. The genie was out of the lamp at that point. The horse had left the barn. It was too late. We could not, at that point, contain the infection anymore using those precision instruments, so we had to go to the blunt tool of social distancing.

That was meant to buy us time. That was meant to prevent our hospitals from becoming overwhelmed, to buy us the time so that we could get our testing, contact tracing, and isolation capacities to a robust enough level and to get our cases low enough that we could once again resort to the precision instruments. We have unfortunately reopened before we met those criteria, and because the reopening was not 
only too fast, but it was done in a hasty manner without having clear guidance on how to do things safely, and I am afraid that we are now at a point that the number of cases are rising again, we still do not have the testing, contact tracing, et cetera, capabilities that we need, and as a result, we are going to see more infections, we will have to resort to lockdowns again. Unfortunately, I do not think we have the political will to do that, and the consequence is going to be that we do have more preventable infections and deaths.

DR. NASH: Dr. Wen, thank you for your really articulate answer, and as Dr. Lee said, I know a soundbite when I hear one. A blunt instrument versus precision, yeah. Baseball bat versus scalpel, you know? That is truly great. And boy, the fact that we do not have a national strategy, that is really going to be a challenge come this late summer, early fall. Fantastic.

Dr. Skochelak, I want to come back to you. Last question to you is about another topic, we sort of touched on it, and we labeled it anxiety. But I want to talk about physician burnout and physician PTSD in the next few months. As one of the key leaders on the education front, what are your concerns at the AMA about burnout and PTSD amongst our ranks?

DR. SKOCHELAK: It is such an important topic, and you have heard so many stories in the news and from your colleagues about what it is like to have to isolate from your family, to not be able to come home, to be worried every day. You heard from the residents starting up who are worried about a variety things. The level of worry, burnout, and anxiety is high.

What we are trying to do on a national level is to work with organizations to help them measure and take action. We have instruments on burnout and resilience that we can share with organizations to survey their learners as well as their workforce to see what the level of burnout and anxiety is.

Dr. Nash, I also have to say one area that we have been especially worried about is our colleagues of color with the added stresses of racism and police brutality that have been so prominent in recent weeks. And we worry that even in education that there may be, like with COVID-19, a disproportionate effect on our communities of color. There may be a disproportionate effect on our students in the education system. This is something that we all need to mindful of and watch for. 
It is the organizations that have to help. You cannot just do yoga and get yourself out of these high-stress situations. You cannot just do mindfulness-meditation to improve burnout. The organizations have to be the entities that we can turn to for help in this important time.

DR. NASH: Well, that is certainly true, and I know Jefferson and every other place, we are having these courageous, difficult conversations. That is part of the organization's reaction. I love the thoughtful expression that you cannot practice mindfulness to get your way out of this one, I do not think.

And I think it also touches on other topics we have talked about here, the trust factor that these nurses, pharmacists, house officers, medical students of color, and others have to feel that there is an organizational response, and that they are not in this fight by themselves, where most of them have been their whole lives. This is going to be an ongoing challenge, for sure.

DR. MEYER: I am very glad to hear Dr. Skochelak talk about our communities of color, but also our colleagues of color. You know, it is hard to combine the horrifying storm of the race riots of the 60s, the depression of the '30s, and the pandemic of 1918 in a three-month period, but that is similar to what we are facing here.

I think it is critical for us to really look at our colleagues. One of the things that we have discovered is that our mortality rate in our hospital is almost threefold that of our baseline mortality rates pre-COVID. Because that has been so compressed in such a short period of time, none of our colleagues really have time to process that in any substantive way. We are very worried about -- and maybe this is a variant of burnout, but really, sort of a PTSD kind of a phenomenon over the next year as people get time to process the mortalities that they have seen in the hospital. And, you know, we are very worried about a burnout factor of, "I just cannot go back to that ICU and face that again if we have another wave in the fall."

And so it is incumbent on all of us to really be proactive about mental health in a profound way, and we are working around group therapy, around a proactive reachout rather than waiting for people to ask for help to try to accomplish that.

DR. NASH: Great. Well, I think we are going to be much more vigilant about these issues that we ever have been before. And again, the organizational support 
that is necessary here and the communication about the support and the followthrough, all of these are going to test leaders across the enterprise.

What is your personal takeaway lesson from the last 90 days that you are willing share with us? What did you learn personally that surprised you, upset you, or gave you new insight, but provided a key personal take-home lesson from the last 90 days? I hope you can share one personal insight, a take-home message that you would be willing to share with our colleagues.

DR. HOLLANDER: My one word that I have learned the most is "communication." Jefferson has done an exceedingly good job through incident command, and through daily briefings in trying to get the word out.

But I think communication goes through the whole thing. There is communication with the community pertaining to social distancing, wearing masks, and staying inside. And unfortunately, again, to use Dr. Wen's term, without getting partisan, there has not been a consistent message across the country.

There is communication with the patients about when and where to get care. Initially, they were all afraid. That seemed reasonable. As we transition back into safety and patients have the ability to safely come back for in-person visits, we need to communicate that. And you heard Dr. Meyer talk about that.

But there is also communication with the providers, administrators, and staff. And what is lost by Zoom meetings is the water-cooler and hallway conversations. I have found that that has created an enormous amount of difficulty as people who like to feel in the loop and hear a little tidbit of information that is normally outside their "swim lane" no longer stay as informed. There are things going on around them, and there is no way to make up for those water-cooler conversations that were some common. So to me, the one word we need to work on, or what I learned most, is the better we communicate, the less problems we will have.

DR. NASH: Outstanding. You cannot over-communicate. That is certainly a takehome message.

DR. WEN: During the course of this pandemic, I have served both a provider and public health person, but also a patient, because I delivered a baby in early April and experienced what it was like being a patient when a lot of us were worried about 
hospitals becoming overwhelmed.

My nurse and I were joking, because she was wearing a mask the entire time due to hospital policy, and she said at some point she was going to see me in a grocery store and want to give me a hug, you know, when we can give each other hugs, and I am going to say, "Well, who is this person coming up to me?" because I never saw her face.

I was worried when I was giving birth about whether I would contract COVID19 from asymptomatic carriers. But then at some point, I remember when my nurse was holding my hand as I was in labor, I thought, "What if I have COVID, and I am going to give COVID to her?"

And it just brings up this point that we are in such different times to be worrying about each other and for each other, and I think this is a time that really underscores the shared humanity that we are experiencing in a very different way. I hope that we come out of this much stronger and feeling this sense of interconnectedness than we ever have.

\section{DR. NASH: Now, that is a wonderful wish, for sure, for the future.}

DR. SKOCHELAK: You know, everything we have been through with the COVID19 pandemic has shined a bright light on what is broken in the health care system, in our education system, and even in our society. Sometimes it feels a little bit disappointing, but at the same time, I ascribe to the philosophy that out of chaos comes opportunity, and the chance to really say, we do not have to accept things as they are but can continue to strive for things as we wish for them to be.

It really challenges all of us to say, we do not want to keep going on without fixing some of these things that absolutely have bothered us before, but in this particularly stressful time, makes us understand, it is not tolerable just to be accepting, but we really have to work for change and improvement.

\section{DR. NASH: And how lucky we are to be in a position to have the capability to make some of those changes, right? Really important.}

DR. LEE: When people feel vulnerable, they focus on what is really important to them. And I think what we have seen since the start of the pandemic is that, without 
exception, as far as I can tell, across the country, health care providers have recognized that what is important is taking care of their patients, taking care of each other, taking care of their communities.

They have not been thinking about what will break even or be profitable under fee-for-service at all, because they knew it was going to be hopeless. They knew that they were going to have enormous deficits, and they were addressing first things first.

I actually think population management is much more important now than it was at the start of 2020, because everyone realizes we have to take care of populations first. We have to meet their needs. And meeting their needs means, you know, cycling back to the beginning, making them feel safe, giving them the kind of contact that telemedicine makes possible without putting themselves at risk and having the frequent contacts that telemedicine makes possible.

Empathy became a front and center priority, and no one has been talking about breaking even under fee-for-service payments. We are going to adjust the payment system now, having recognized what is really important because to a certain extent our vulnerability helps us to see things more clearly.

DR. NASH: Great. Dr. Meyer, something that never happens in your house, you get the last word.

DR. MEYER: That is the truth, Dr. Nash. I would say nothing sharpens the mind like a true crisis. We have spent years talking about unnecessary variation in health care. One of the things I would say I profoundly learned is that this kind of crisis allowed us to change standards of care literally in 24 hours across the entirety of our system.

We cannot lose that opportunity, so I think the lesson for me has been that there are no more excuses about how hard or politically complicated necessary change is, regardless of the thousand points of veto around them. Let's get rid of unnecessary variation in health care. We proved we could do it for COVID-19. Why can we not do it for everything else?

DR. NASH: Wonderful. Well, colleagues, I want to just end the way we started. Thank you so much for carving time out of your super-busy schedules. It is so great to all be together. Stay safe and really get out there and remind everybody to please wear a mask. If you could do anything, that is the most important darn 
thing.

So stay safe, stay sane. This was just a wonderful conversation. Thanks again.

\section{Reference}

1. Rosenstock L, Silver GB, Helsing K, et al. On linkages: confronting the public health workforce crisis: ASPH statement on the public health workforce. Public Health Rep 2008;123:395-398. 